\title{
Triatoma jatai sp. nov. in the state of Tocantins, Brazil (Hemiptera: Reduviidae: Triatominae)
}

\author{
Teresa Cristina Monte Gonçalves ${ }^{1}$, Simone Caldas Teves-Neves ${ }^{1}$, Jacenir Reis dos Santos-Mallet ${ }^{1}$, \\ Ana Laura Carbajal-de-la-Fuente ${ }^{2}$, Catarina Macedo Lopes ${ }^{1 /+}$
}

\author{
${ }^{1}$ Laboratório de Transmissores de Leishmanioses, Setor de Entomologia Médica e Forense, Instituto Oswaldo Cruz-Fiocruz, \\ Rio de Janeiro, RJ, Brasil '2Laboratório de Eco-epidemiologia, Departamento de Ecología, Genética y Evolución, \\ Facultad de Ciencias Exactas y Naturales, Universidad de Buenos Aires, Buenos Aires, Argentina
}

Triatoma jatai sp. nov. is the first new species of triatomine to be described in the state of Tocantins, in the northern region of Brazil. It was caught on rock outcrops in the wild environment and, more recently, invading homes. While T. jatai sp. nov. is morphologically similar to Triatoma costalimai, it is distinguished by its general colouring, differences in the blotches on the connexivum, wing size in females and external structures of the male genitalia. The type series has been deposited in the Entomological Collection and Herman Lent Collection, Oswaldo Cruz Institute-Oswaldo Cruz Foundation, Rio de Janeiro, Brazil.

Key words: Triatoma - taxonomy - Chagas disease vector - biodiversity - Brazil

The state of Tocantins (TO) is located in the northern region of Brazil; $91 \%$ of its territory is formed by the Cerrado (savanna-like) biome and the remaining $9 \%$ by the Amazonian biome (IBGE 2004). In 2006, the 139 municipalities that make up this state were classified regarding their degree of risk of vector transmission of Chagas disease, such that $24.47 \%$ presented a high risk, $52.51 \%$ medium risk and $23.02 \%$ low risk, with a triatomine fauna consisting of 12 species distributed across different ecotopes (Costa et al. 2003, Oliveira et al. 2008). The southern and southeastern regions of TO, which are considered to be endemic for Chagas disease, are within the Cerrado biome and are composed of a variety of vegetation types, such as cerrado (lightly wooded savanna-like terrain), cerradão (more heavily wooded savanna-like terrain), park-like terrain, campo limpo (savanna grassland) and campo rupestre (rocky open terrain). This last type consists of large numbers of calcareous rock outcrops scattered across the region that form the so-called "limestone scrub", which has the capacity to provide shelter for triatomine fauna and its food sources.

Specimens of Triatoma costalimai Verano \& Galvão, 1959 have been caught in the municipalities of Aurora do Tocantins and Paranã, located in the southeast and south of the state. This species is now included in the species subcomplex matogrossensis, according to its molecular and biogeographical characteristics (Schofield \& Galvão 2009).

Also in Paranã, triatomine specimens similar to $T$. costalimai, but unidentifiable from the classical morphological patterns have been caught.

doi: 10.1590/0074-0276108042013006

Financial support: FIOCRUZ/ENERPEIXE SA, SES-TO

+ Corresponding author: aniratac@ioc.fiocruz.br

Received 16 October 2012

Accepted 30 November 2012
According to Dujardin et al. (2010), the morphometric geometric of wings allows observing conformational changes undetectable by traditional morphological methods and has been used for taxonomic identification of cryptic species in Triatominae for the genus Rhodnius (Matias et al. 2001, Villegas et al. 2002, Rosa et al. 2012), Triatoma (Gumiel et al. 2003, Carbajal de la Fuente 2007, Carbajal de la Fuente et al. 2011) and Mepraia (Campos et al. 2011). The morphology and the morphometric geometric of wings are studied and described herein as bellowing to a new species of the genus Triatoma Laporte, 1832 and proposed a new taxonomic key for Triatoma matogrossensis subcomplex based on Obara et al. (2012).

\section{MATERIALS AND METHODS}

Specimens of Triatoma jatai $\mathrm{sp}$. nov was captured on rock outcrops at four sites: on the ranch Fazenda Jatai (12 $\left.42^{\prime} 40^{\prime \prime} \mathrm{S} 48^{\circ} 13^{\prime} 12^{\prime \prime} \mathrm{W}\right)$, bordering the TO-387/296 highway on the stretch between Paranã and São Salvador (12 $40^{\prime} 10^{\prime \prime} \mathrm{S} 48^{\circ} 12^{\prime} 16^{\prime \prime} \mathrm{W}$ and $\left.12^{\circ} 40^{\prime} 40^{\prime \prime} \mathrm{S} 48^{\circ} 11^{\prime} 36^{\prime \prime} \mathrm{W}\right)$ and on Fazenda Vereda, Bangue $\left(12^{\circ} 26^{\prime} 05^{\prime}\right.$ 'S $\left.48^{\circ} 03^{\prime} 59^{\prime \prime} \mathrm{W}\right)$. All of these sites are within the municipality of Paranã (Figs 1, 2). T. costalimai from Aurora do Tocantins and Triatoma williami obtained from the National Laboratory and International Reference on Taxonomy of Triatominae (LNIRTT), Oswaldo Cruz Foundation (Fiocruz), Rio de Janeiro (RJ), Brazil, were used to comparison (license SISBIO 18014-1). The morphometric study of $T$. jatai $\mathrm{sp}$. nov. and T. costalimai species was conducted on 30 males and 30 females on stereoscopic microscopy (Zeiss - SV6 ${ }^{\circledR}$ ). The male genital structures analyses were done on 10 specimens of T. jatai sp. nov. comparing with T. costalimai (Lent \& Jurberg 1980).

The geometric morphometric analysis of wings was performed with $T$. jatai sp. nov. (85 females and 67 males), T. costalimai (54 females and 67 males), T. williami (5 females and 10 males) and Triatoma sordida (14 females and 6 males), as the outgroup. The wings were extirpated 


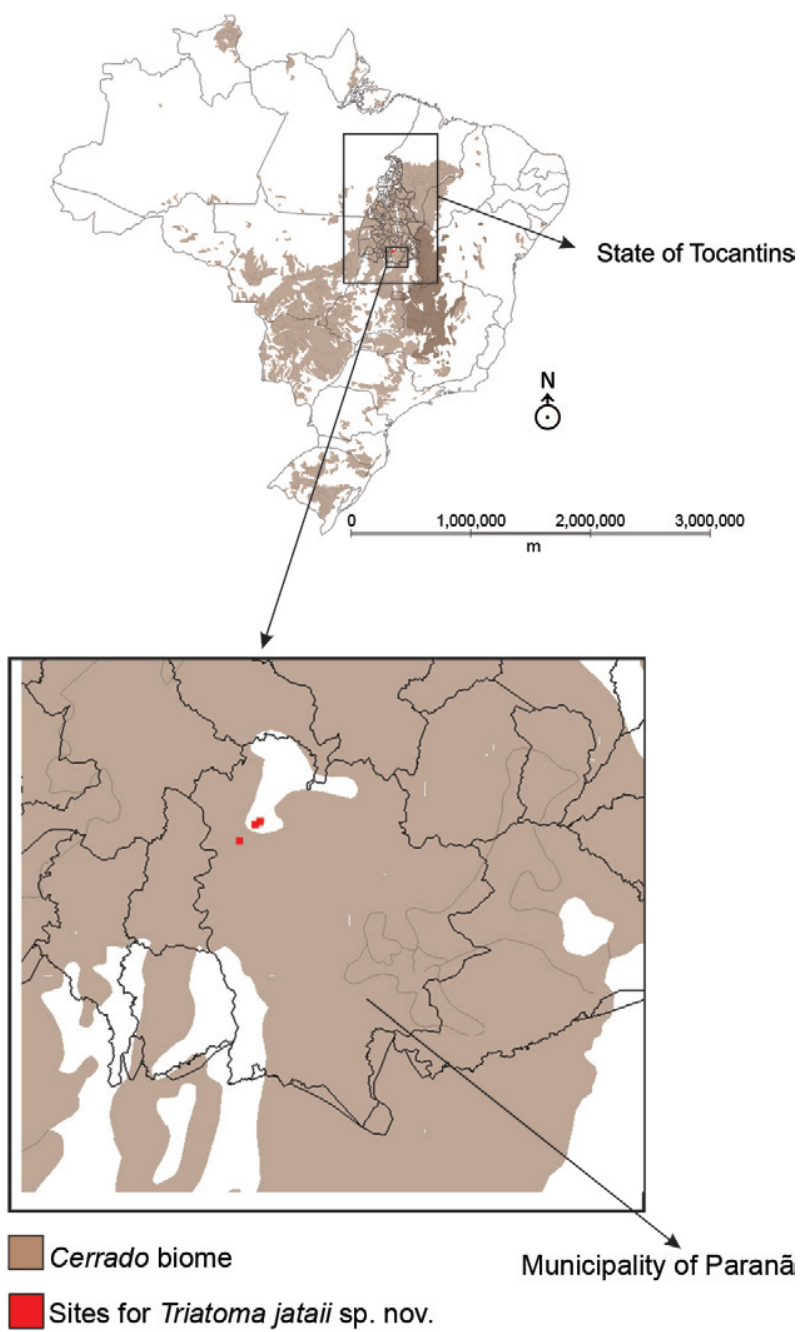

Fig. 1: map showing Cerrado biome and sites of capture of Triatoma jatai sp. nov, municipality of Paranã, state of Tocantins, Brazil.
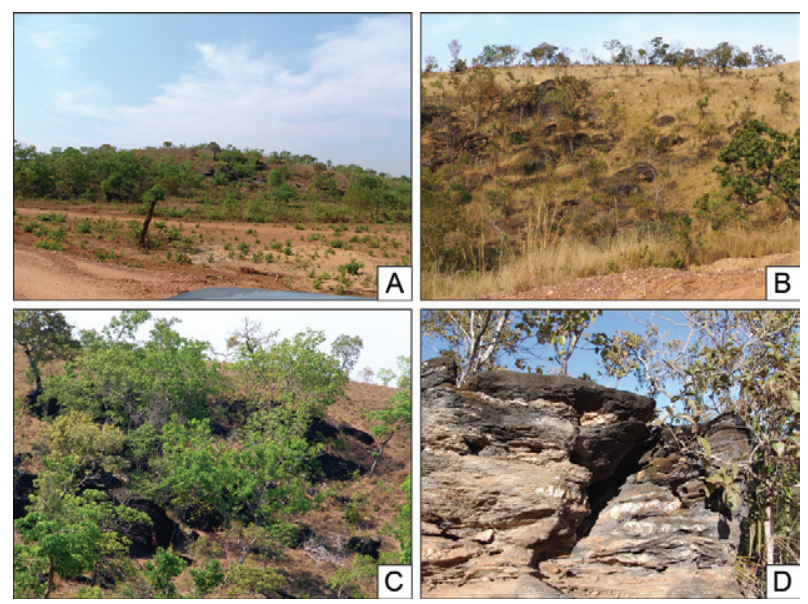

Fig. 2A: site of capture view; B-D: details of rock outcrops where Triatoma jatai sp. nov. was captured on the ranch Fazenda Jatai, state of Tocantins, Brazil. with forceps and mounted among microscope slides and cover-slips with alcohol 70\%. Photographs were taken using digital camera (Sony DSC - S70) and coupled manually on the ocular of a stereomicroscope Zeiss - SV6 ${ }^{\circledR}$. We used the 7 type-1 landmarks (vein intersections) according to Bookstein (1990). For comparison of wing size we used the isometric estimator known as centroid size (CS) derived from coordinates data. CS is defined as the square root of the sum of the squared distances between the centre of the configuration of landmarks and each individual landmark (Bookstein 1990). Shape variables (partial warps plus uniform components) were obtained using the Generalized Procrustes Analysis superimposition algorithm (Rohlf 1996). The method is based in the superimposition of each individual using least-square, eliminating effects of scale, orientation and position of the objects. The shape variables define the positional changes at each landmark in relation to a consensus shape.

Kruskal-Wallis tests corrected by Bonferroni method were used to analyse the CS between the analysed species. The Mahalanobis distances derived from shape variables were used to explore the shape proximity between species. Their statistical significance was computed by permutation tests (1,000 runs each) and corrected by Bonferroni method. These distances were used in unweighted pair-group method with arithmetic average (UPGMA) cluster analyses to produce dendrograms. Discriminant analyses were performed to evaluate the existence of significant differences to interspecific level and to reclassify the individuals using the discriminant functions and Mahalanobis distances.

For morphometric analysis we used CLIC v45 package developed by JP Dujardin (life.bio.sunysb/morpho). Statistics analysis was executed with JMP v4 (SAS Institute, Inc, Cary, NC, USA).

The material is deposited in the Entomological Collection, Oswaldo Cruz Institute (CEIOC), Fiocruz, and Herman Lent Collection, LNIRTT. The morphological and morphometrics descriptions are according to the taxonomic characteristics for the Triatominae proposed by Verano and Galvão (1959) and Lent and Wygodzinsky (1979).

\section{RESULTS}

\section{T. jatai Gonçalves, Teves-Neves, Santos-Mallet, Carbajal-de- la-Fuente and Lopes, sp. nov.}

(Fig.3)

Diagnosis - T. jatai sp. nov. (Fig. 3) can be distinguished from the morphologically closer species $T$. costalimai (Fig. 4) mainly by the smaller size (Tables I, II) and general brown colour; by the pilosity of rostral segments, by the size and colour of the connexival spots, which are yellow, above an intersegmental suture, which is brown; by the shorter wing size of the females, finishing at the basal third of the seventh tergite and by the smaller size and shape of the structures of male external genitalia (Table III).

Length: male $18.6 \mathrm{~mm}$, female $20.15 \mathrm{~mm}$; length and width of head, length of eye, synthlipsis, rostral segments, length and width of pronotum and width of abdomen are in the Tables I, II. 
Head: brown, elongate, slightly rugose. Head four times longer than width (1:0.23) and longer than pronotum (1:0.7) or as long as the pronotum and scutellum together, without apical process of scutellum, covered with short setae; $1+1$ glabrous area extending from the base to the antenniferous tubercles and to the ocelli. Anteocular region four times longer than postocular region (1:0.22). Clypeus narrow, extending gradually from the middle region. Genas sharp, projecting beyond apex of clypeus. Jugum angular apically. Eyes in lateral view attaining level of undersurface and remote from level of upper surface of head. Ratio of width of eye to synthlipsis 1:0.5. Antenniferous tubercles inserted into the middle of anteocular region of head. First antennal segment brown, reaching the middle of clypeus, with scattered setae in row. Second segment brown, hirsute, bristles longer than the diameter of the segment. Third segment with base dark and the remainder clear. Fourth segment clear. Both third and fourth segments covered with sparse short and long bristles, ar- ranged perpendicularly to the segment. Ratio of antennal segments 1:4.5:2.7:2.4. Rostrum with the same colour as head, extending to prosternum, with sparse short hairs on first and second segments; third segment with numerous hairs. Ratio of rostral segments 1:3:1.

Pronotum: brown, rugose, length and width similar. Anterior lobe with 1+1 discal tubercles; lateral tubercles absent. Submedian carinae almost reaching the posterior margin of posterior lobe. Humeral angles rounded; may present 1+1 light spot.

Scutellum: brown, rugose, with a central V-shaped depression. Apical process cylindrical, as long as main body of scutellum; apex slightly elevated, rounded.

Hemelytra: males attaining or almost attaining apex of seventh urotergite. Females short, attaining basal third or middle of seventh urotergite. Corium and clavus brown; subcosta light. Corium with $2+2$ ochre spots on basal and apical regions. Membrane gray with black veins.
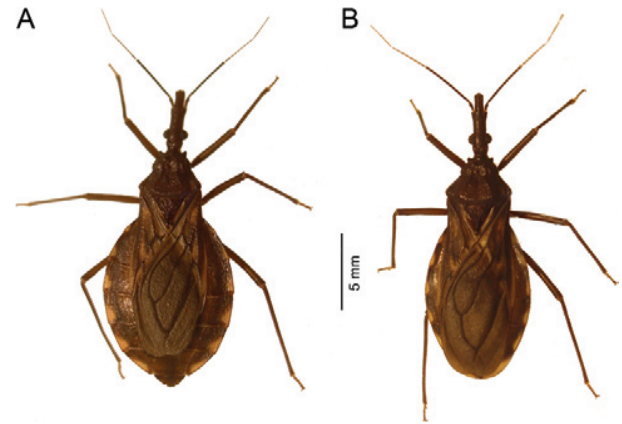

Fig. 3: Triatoma jatai sp. nov. A: female; B: male.
A

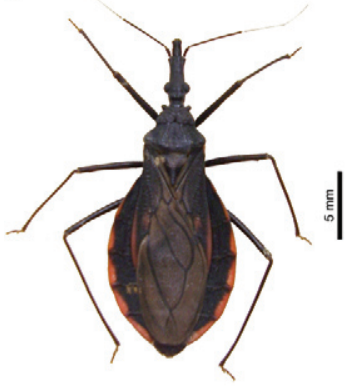

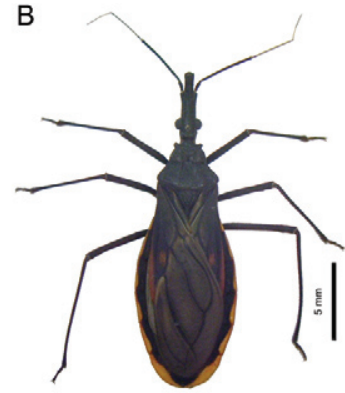

B

Fig. 4: Triatoma costalimai. A: female; B: male.

\section{TABLE I}

Measurements (in mm) of Triatoma jatai sp. nov. and Triatoma costalimai female captured in the municipality of Paranã and Aurora do Tocantins, state of Tocantins, Brazil

\begin{tabular}{|c|c|c|c|c|c|c|c|c|c|c|}
\hline \multirow{2}{*}{$\begin{array}{l}\text { Gender } \\
\text { Variables }\end{array}$} & \multicolumn{5}{|c|}{ T. jatai sp. nov. } & \multicolumn{5}{|c|}{ T. costalimai } \\
\hline & Min & Max & $\mathrm{X}$ & SD & $\mathrm{S}^{2}$ & Min & Max & $X$ & SD & $\mathrm{S}^{2}$ \\
\hline Total length & 17.2 & 28.5 & 20.15 & 2.027 & 4.252 & 22.5 & 25.9 & 24.87 & 1.162 & 1.352 \\
\hline Width of abdomen ${ }^{a}$ & 6.3 & 9.4 & 8.15 & 0.698 & 0.504 & 8.4 & 10.7 & 9.55 & 0.879 & 0.772 \\
\hline Length of pronotum & 2.3 & 3.2 & 2.79 & 0.208 & 0.044 & 3.1 & 3.5 & 3.27 & 0.160 & 0.025 \\
\hline Width of pronotum & 2.3 & 3.1 & 2.62 & 0.260 & 0.069 & 2.6 & 3.2 & 2.95 & 0.207 & 0.042 \\
\hline Length of head & 3.9 & 4.4 & 4.06 & 0.145 & 0.021 & 4.1 & 5.1 & 4.81 & 0.376 & 0.141 \\
\hline Width of head & 0.8 & 1.0 & 0.90 & 0.047 & 0.002 & 1.0 & 1.1 & 1.08 & 0.037 & 0.001 \\
\hline Synthlipsis & 0.8 & 1.0 & 0.85 & 0.056 & 0.003 & 0.9 & 1.1 & 0.97 & 0.075 & 0.005 \\
\hline Width of eyes & 0.4 & 0.5 & 0.40 & 0.017 & 0.000 & 0.5 & 0.5 & 0.50 & 0.000 & 0.000 \\
\hline Length of 1st rostral segment & 0.8 & 1.1 & 0.94 & 0.080 & 0.006 & 1 & 1.2 & 1.07 & 0.075 & 0.005 \\
\hline Length of 2 nd rostral segment & 2 & 3.0 & 2.54 & 0.223 & 0.051 & 3 & 3.3 & 3.14 & 0.127 & 0.016 \\
\hline Length of 3 rd rostral segment & 0.8 & 1.0 & 0.92 & 0.071 & 0.005 & 1 & 1.2 & 1.08 & 0.089 & 0.008 \\
\hline
\end{tabular}

$a$ : all the differences between species are significant, except for the female width abdomen (analysis of variance - $\mathrm{p}<0.05$ ); Max; maxima; Min: minimum; SD: standard deviation; $\mathrm{S}^{2}$ : variance; X: average. 
Legs: brown with short hairs in row. Fore femora eight times as long as wide. Fore and mid femora with a couple of weak denticles subapically. Males with spongy fossulae on tibiae of foreleg; absent in female.
Abdomen: convex, polished, covered by short hairs, appearing glabrous. Spiracles clear adjoining connexival suture. Urosternites brown. Connexivum predominantly brown with basal clear triangular spots of variable width,

\section{TABLE II}

Measurements (in mm) of Triatoma jatai sp. nov. and Triatoma costalimai male captured in the municipality of Paranã and Aurora do Tocantins, state of Tocantins, Brazil

\begin{tabular}{|c|c|c|c|c|c|c|c|c|c|c|}
\hline \multirow{2}{*}{$\begin{array}{l}\text { Gender } \\
\text { Variables }\end{array}$} & \multicolumn{5}{|c|}{ T. jatai sp. nov. } & \multicolumn{5}{|c|}{ T. costalimai } \\
\hline & Min & Max & $\mathrm{X}$ & SD & $\mathrm{S}^{2}$ & Min & Max & $\mathrm{X}$ & SD & $\mathrm{S}^{2}$ \\
\hline Total length & 16.6 & 21.9 & 18.64 & 1.249 & 1.561 & 19.9 & 22.8 & 21.47 & 0.784 & 0.615 \\
\hline Width of abdomen ${ }^{a}$ & 6.0 & 7.9 & 6.94 & 0.486 & 0.236 & 5.6 & 8.4 & 6.99 & 0.834 & 0.696 \\
\hline Length of pronotum & 2.6 & 3.2 & 2.88 & 0.179 & 0.032 & 2.2 & 3.6 & 3.08 & 0.303 & 0.092 \\
\hline Width of pronotum & 2.2 & 3.0 & 2.55 & 0.188 & 0.035 & 2.5 & 3 & 2.77 & 0.176 & 0.031 \\
\hline Length of head & 3.6 & 4.2 & 3.91 & 0.131 & 0.017 & 4.1 & 4.8 & 4.51 & 0.152 & 0.023 \\
\hline Width of head & 0.7 & 0.9 & 0.84 & 0.056 & 0.003 & 0.9 & 1.0 & 0.96 & 0.047 & 0.002 \\
\hline Synthlipsis & 0.7 & 0.8 & 0.76 & 0.049 & 0.002 & 0.8 & 1.0 & 0.87 & 0.073 & 0.005 \\
\hline Width of eyes & 0.4 & 0.5 & 0.40 & 0.017 & 0.000 & 0.4 & 0.5 & 0.47 & 0.043 & 0.002 \\
\hline Length of 1 st rostral segment & 0.5 & 1.0 & 0.90 & 0.116 & 0.013 & 0.8 & 1.2 & 1.00 & 0.090 & 0.008 \\
\hline Length of 2 nd rostral segment & 2.0 & 2.9 & 2.45 & 0.214 & 0.046 & 2.7 & 3.2 & 2.94 & 0.124 & 0.016 \\
\hline Length of 3 rd rostral segment & 0.7 & 1.0 & 0.88 & 0.077 & 0.005 & 0.6 & 1.0 & 0.98 & 0.099 & 0.010 \\
\hline
\end{tabular}

$a$ : all the differences between species are significant, except for the male width abdomen (analysis of variance - $\mathrm{p}<0.05$ ); Max; maxima; Min: minimum; SD: standard deviation; $\mathrm{S}^{2}$ : variance; $\mathrm{X}$ : average.

TABLE III

Morphological differences between Triatoma jatai sp. nov. and Triatoma costalimai Verano \& Galvão, 1979

\begin{tabular}{|c|c|c|}
\hline General aspects & T. jatai sp. n. & T. costalimai \\
\hline General colour & Brown & Dark brown or black \\
\hline Rostrum & $\begin{array}{l}\text { Second and third rostral segments with } \\
\text { short hairs, numerous on third }\end{array}$ & $\begin{array}{l}\text { Second and third rostral segments } \\
\text { with numerous long hairs }\end{array}$ \\
\hline Hemelytra & $\begin{array}{c}\text { Corium with } 2+2 \text { ochre spots on basal and } \\
\text { apical regions. Males hemelytra attaining } \\
\text { or almost attaining apex of seventh urotergite, } \\
\text { females attaining basal third } \\
\text { or middle of seventh urotergite }\end{array}$ & $\begin{array}{l}\text { Corium with } 2+2 \text { red spots on basal and apical } \\
\text { regions. Males and female hemelytra } \\
\text { attaining apex of seventh urotegite }\end{array}$ \\
\hline Connexivum & $\begin{array}{l}\text { Connexivum brown with apical clear } \\
\text { triangular spot close to the basal } \\
\text { intersegmental suture }\end{array}$ & $\begin{array}{l}\text { Connexivum entirely dark brown or black, } \\
\text { with orange-red marking of variable width } \\
\text { extending along outer connexival border, } \\
\text { interrupted by very narrow black bands } \\
\text { on intersegmental suture }\end{array}$ \\
\hline Tibiae & $\begin{array}{l}\text { Spongy fossulae on fore tibiae } \\
\text { of male, absent in female }\end{array}$ & $\begin{array}{l}\text { Spongy fossulae on fore and mid tibiae } \\
\text { of male, absent in female }\end{array}$ \\
\hline Median process of pygophore & Triangular with arcuate base & Y shape with arcuate base \\
\hline Vesica & $\begin{array}{l}\text { Vesica with recesses; } 1+1 \text { submedian and one } \\
\text { in base; hooked in side view, elongated with } \\
\text { flat base and pointed apex in dorsal view }\end{array}$ & $\begin{array}{l}\text { Vesica without recesses, with flat base, } \\
\text { curved in side view with rounded apex }\end{array}$ \\
\hline Phallosoma & Pentagonal & Ovoid \\
\hline
\end{tabular}


near the intersegmental suture. Females with abdomen wider than in males $(1: 0.8)$.

Male genitalia: parameres cylindrical; upper third curved with laminar projections at $90^{\circ}$. Middle and inner surface hairy; outer side glabrous and hirsute on edge (Fig. 5). Median process of pygophore triangular with arcuate base (Fig. 6). Phallus ventral, showing pentagonal phallosoma (Figs 7, 8). Phallus lateral view showing elongated hollow struts; lateral arms attached apically and slightly separated in the base (Figs 9, 10). Phallus dorsal view with endosomal aliform process, striated throughout its length; apical third with conspicuously sclerotised projections (Figs 11, 12). Vesica with recesses; $1+1$ submedian and one in base; hooked in side view, elongated with flat base and pointed apex in dorsal view (Figs 9, 11, 13). Gonopore process cylindrical, hollow; outer edges removed almost reaching the median basal plate (Figs 7, 9). Median basal plate rectangular, welded to basal plate (Fig. 7).

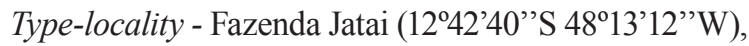
municipality of Paranã.
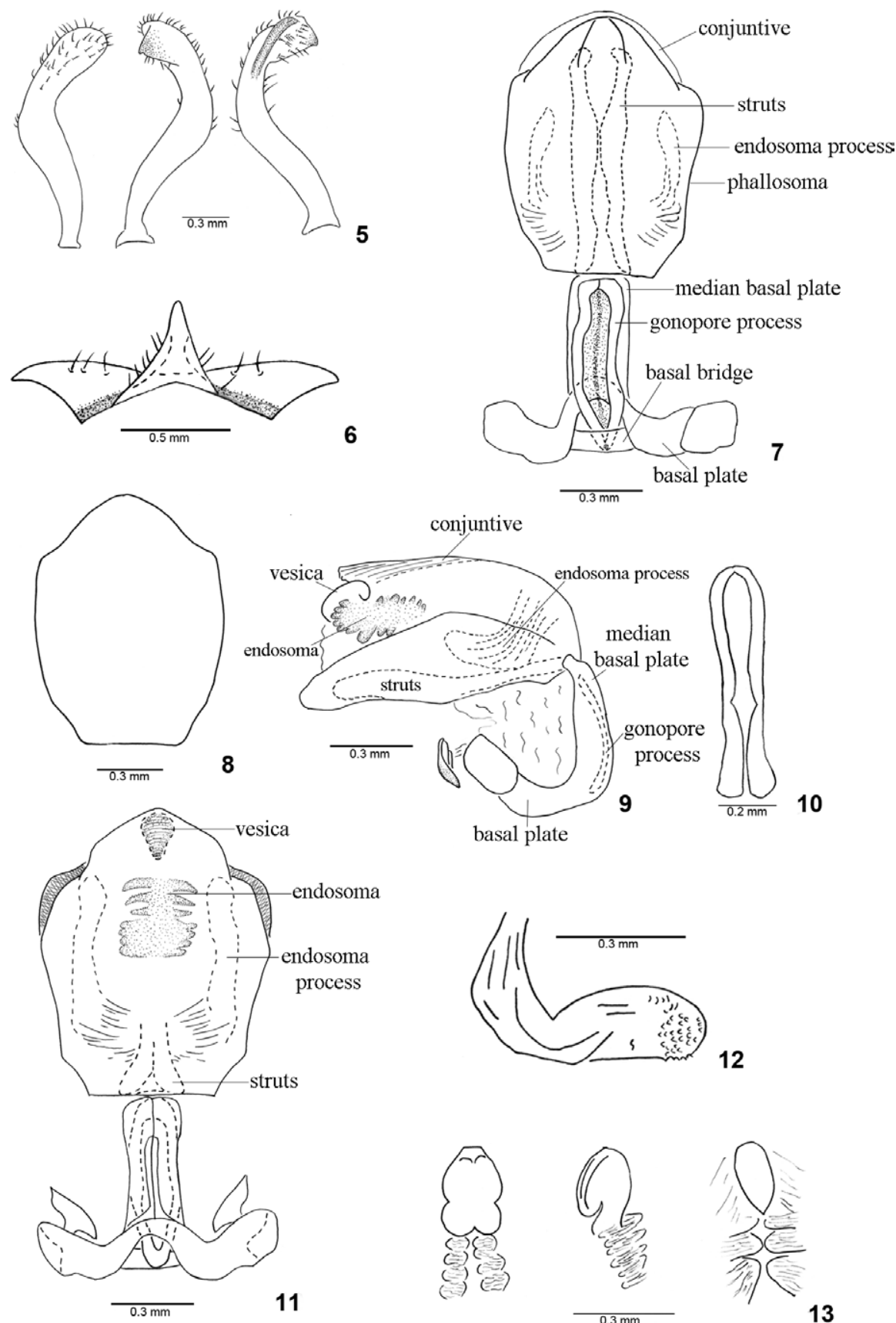

conjuntive
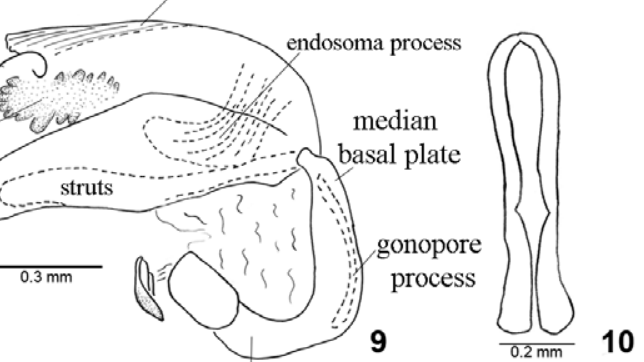

basal plate

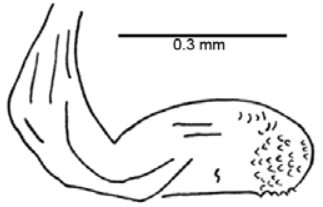

12
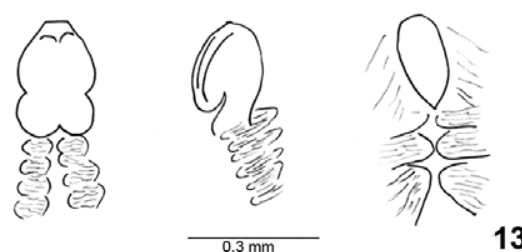

Figs 5-13: Triatoma jatai sp. nov.; 5: parameres, side view, internal view and external view; 6: median process of pygophore; 7: phallus, ventral view; 8: phallosoma; 9: phallus, lateal view; 10: struts; 11: phallus, dorsal view; 12: endosoma process; 13: vesica, ventral, lateral and dorsal view. 
Type data and depository - Holotype: female (27 IX 2007) and seven paratypes (4 males and 3 females) from Fazenda Jatai (12 $2^{\circ} 42^{\prime} 40^{\prime}$ 'S $\left.48^{\circ} 13^{\prime} 12^{\prime \prime} \mathrm{W}\right)$, municipality of Paranã; four paratypes ( 2 males and 2 females) from the same locality registrations 3401-3404 of Herman Lent Collection (LNIRTT/IOC).

Other material examined - One male for the description; four males for the genitalia study, 30 males and 30 females for the morphometric study.

\section{Distribution - Municipality of Paranã (Fig. 1).}

Etymology - The specific epithet is a noun in apposition referring to the capture site, Fazenda Jatai in the type locality, to where the local population was relocated during the construction of the Aproveitamento Hidrelétrico Peixe Angical, TO.

Key to the species of Triatoma matogrossensis subcomplex (based on Obara et al. 2012)

1. Pronotum brown or with marking 2

- Pronotum entirely black

2. Legs brown, fore and mid femora with a couple of weak denticles subapically; males with spongy fossulae on tibiae of foreleg, absent in female; hemelytra with corium and clavus brown and membrane gray with black veins, hemelytra of female short, attaining basal third or middle of seventh urotergite; connexivum predominantly brown with clear triangular spots of variable width, near the basal intersegmental suture T. jatai

- Legs, hemelytra and connexival spots different from the description above 3

3. Pronotum and legs reddish brown; trochanters yellowish; femora with small tubercles; connexivum dark, with subtriangular orange mark on each segment, ventrally attaining the connexival suture; head with anteocular region 6 or more times longer than postocular $(1: 0.16)$ T. jurbergi

- Pronotum dark brown or reddish brown with 1+1 light spots on ad-humeral region; legs light yellowish brown with markings or annulus dark coloured; femora predominantly light coloured; connexivum yellow or yellowish brown with a straight dark strip ...

T. matogrossensis

4. Tibiae brown: head, pronotum, pleura, prosternum and abdomen black; anteocular region 4.6 times longer than postocular; eyes in lateral view not surpassing the superior limit of the head; connexivum ventrally, without marks; connexivum dorsal almost without marking except small black line in intersegmental suture T. vandae

- Tibiae uniformly coloured or with spot apically or with light coloured annulus subapically .......................... 5

5. Trochanters and base of femora yellow; legs dark brown; hemelytra attaining the apex of seventh urotergite in both sexes; transversal dark markings of connexivum approximately in shape of musical notes; head longer than pronotum (1:0.9) T. deaneorum

- Femora entirely dark, trochanters partially or en-

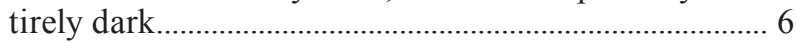

6. First antennal segment distant from the level of apex of clypeus
- First antennal segment almost attaining the level of apex of clypeus; apical process of scutellum short, shorter than the half of entirely scutellum; hemelytra attaining the apex of dorsal abdomen; corium with basal half light yellow; apical half of corium and membrane brown; head with anteocular region 4 times longer than postocular. Large eyes just surpassing inferior border of head in lateral view. Apical process of scutellum horizontal T. guazu

7. Corium of hemelytra black with orange or reddish spots on apical half; connexivum black and edge of border orange, interrupted by very narrow black bands at level of intersegmental suture; at internal limit connexivum entirely black T. costalimai

- Corium of hemelytra yellow or orange with dark veins; connexivum different; legs black, anterior and median femora with small tubercles

8. Connexivum pale yellow with small markings at intersegmental suture along the external border and a dark line along connexival suture; membrane grayish brown; anteocular region 4 times longer than postocular .................................................................. T. williami

- Connexivum completely pale yellow; dark suture visible only ventrally; membrane fumose; anteocular region 5 times longer than postocular. T. baratai

Size variation - The Kruskal-Wallis test revealed significant differences $(\mathrm{p}<0.001)$ between $T$. costalimai, T. williami, T. jatai $\mathrm{sp}$. nov. and T. sordida being markedly lower wings of T. jatai sp. nov. (Fig. 14). The female wings of T. jatai sp. nov. are significantly smaller than the males $(\mathrm{p}<0.001)$ (Fig. 14). No significant differences were found in the CS of males and females belonging to the species T. sordida.

Shape variables - The individuals projected onto the two first canonical factors show a separation between $T$. jatai sp. nov. and T. costalimai species. However, exist an overlap between the polygons from $T$. williami and $T$. sordida species (Fig. 15). The permutation test corrected by Bonferroni showed that $T$. jatai sp. nov. is significantly different from other species $(\mathrm{p}<0.001)$. The derived UPGMA dendogram showed a clear separation between species (Fig. 16). Rates of reclassification of individuals to $T$. jatai sp. nov. and T. costalimai were considered satisfactory (48-64\%) and for T. willami were acceptable (70\% and $80 \%$ ) and for the females of T. sordida lower $(35 \%)$ and higher for males $(82 \%)$. The contribution of canonical factors resulted in 59\%, 30\% and 6\% for the first three factors.

\section{DISCUSSION}

A study on the triatomine fauna of the southern and southeastern regions of TO was conducted between 20042008, covering a total of 11 municipalities: Peixe, São Salvador, Paranã, São Valério, Ponte Alta do Bom Jesus, Taguatinga, Aurora do Tocantins, Lavandeira, Combinado, Novo Alegre and Arraias (Gonçalves et al. 2006).

In the southeastern region, in the municipalities of Ponte Alta do Bom Jesus, Taguatinga, Aurora do Tocantins and Paranã, specimens of T. costalimai infected with Trypanosoma cruzi (Chagas 1909) were collected 
from wild environments among volcanic rock outcrops. Aurora do Tocantins was the only municipality in which specimens of this species positive for T. cruzi were also caught in peridomestic areas.

The type locality for T. costalimai is the district of Manhã, municipality of Taguatinga, state of Goiás, and specimens were collected from limestone outcrops (Verano \& Galvão 1959).

The specimens of T. jatai sp. nov., which were restricted to the municipality of Paranã, were also caught in the wild environment but, unlike $T$. costalimai in this region, among limestone outcrops and without the presence of infection by T. cruzi. To investigate infection due to T. cruzi, faeces and/or urine of both species were obtained by means of abdominal compression and were seeded into Novy-MacNeal-Nicolle culture medium.

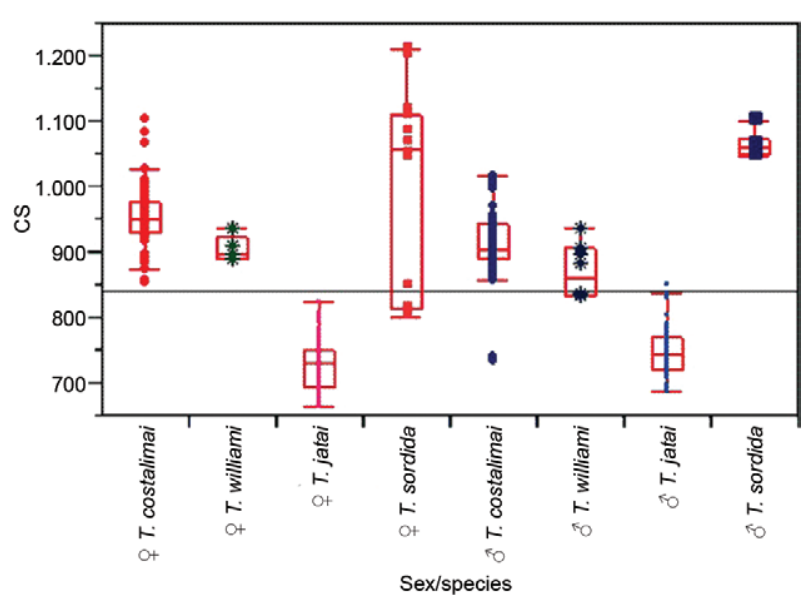

Fig. 14: variation of size [centroid size (CS)] among Triatoma jatai sp. nov., Triatoma costalimai, Triatoma williami and Triatoma sordida. Box plot indicate median of group as a line in the middle of quartiles (25 and 75 closed the box and 10 and 90 as lines in the extremes of each box). Line dot denotes the grand mean. The point at centre of the boxes shows the distribution of specimens.

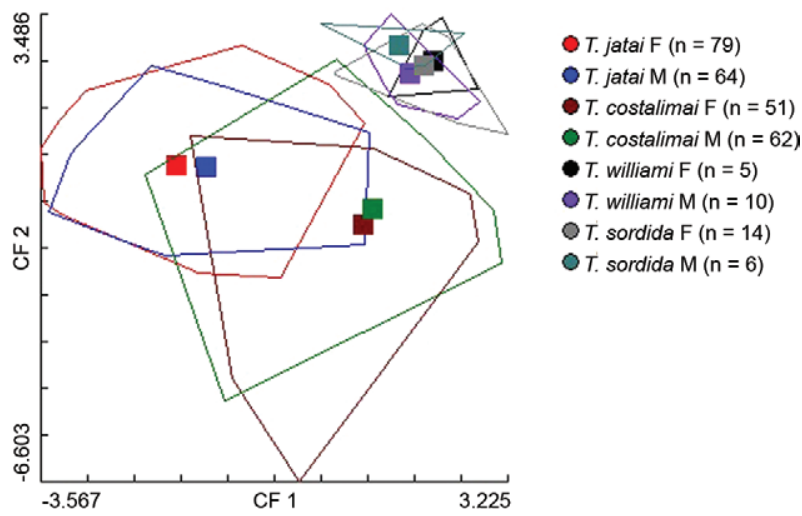

Fig. 15: canonical variate analysis of Triatoma jatai sp. nov., Triatoma costalimai, Triatoma williami and Triatoma sordida. Centroid distribution (multivariate mean) on canonicals factors (CF) 1 and 2. F: female; M: male.
Recently, three adult specimens (1 male and 2 females) were also collected from inside a home [A Feitosa, unpublished observations (Health Department of the State of Tocantins)].

Both species are too close morphologically, but may be differentiated mainly by the size, general colour, size and shape of wings, connexivum and intersegmental sutures. T. jatai sp. nov. is brown and significantly smaller than $T$. costalimai, which present the general colour black. The wings of female are visibly shorter, ending at the level of the seventh urotergite, while in T. costalimai the wings cover the eighth urotergite. T. jatai sp. nov. show a connexivum with subtriangular yellow connexival blotches of varying width, located in the apical region proximal to the chestnut brown intersegmental sutures, different of T. costalimai, where the connexivum have a reddish outline, weakly interrupted at the level of the intersegmental sutures by a black band and completely black at the internal limit with the abdomen.

Structures of the male external genitalia of T. jatai specimens did not show intraspecific variation, but they are smaller than T. costalimai described by Lent and Jurberg (1980). T. jatai shows the median process of pygophore is triangular; the vesica show recesses, hooked in side view, the phallosoma has a trapezoidal shape, while $T$. costalimai the median process of pygophore has any shape, the vesica show no recesses, less hooked in side view, and the phallosoma is ovoid.

Pires et al. (1995) identified differences of genital structures for two populations of Triatoma infestans as well Costa et al. (1997) to Triatoma brasiliensis population. However, the last author state that a large and representative samples should be examinated before using for diagnosis. This corroborates the results of the present study where a multidisciplinary analysis was important to a taxonomic identification.

Regarding the CS, females of T. jatai sp. nov. have smaller wings than $T$. costalimai and T. williami. Sexual dimorphism in body size may be observed in both $T$. jatai sp. nov. and T. costalimai species, as observed for other triatomine species where females are larger than males (Márquez et al. 2011, Gaspe et al. 2012). Significant differences were observed comparing the sexes between the species where T. jatai sp. nov. was significantly lower than T. costalimai. Only the abdomen width was bigger in T. jatai sp. nov. males, which may be associated to nutritional status, which does not influence the other morphological characteristics.

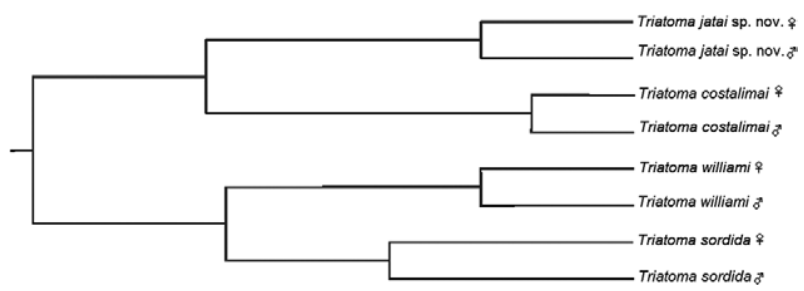

Fig. 16: unweighted pair-group method with arithmetic average dendogram derived from Mahalanobis distances based on wings shape. 
The geometric morphometrics wings allowed to differentiate $T$. jatai sp. nov. from the species $T$. costalimai and $T$. williami, which are close morphologically (Lent \& Wygodzinsky 1979).

The wings shape showed the separation between $T$. jatai sp. nov. and the remaining species. Thus, the UPGMA Mahalanobis distances tree evidenced that T. jatai sp. nov. and T. costalimai clustered in different clades, corroborating the differences found by other tools presented in this paper, showing once again the contribution of geometric morphometrics to clarify taxonomic differences.

The main vector causing endemicity of Chagas disease in the southeastern region of TO is the species $T$. infestans (Klug 1834), which was eliminated from domestic environments in 2002 (Oliveira et al. 2008). In turn, the native species started to occupy the vacant ecotopes and participate in transmission of T. cruzi as commented by Costa and Lorenzo (2009). T. costalimai is now taking on epidemiological importance because of the numbers of notifications of colonisation by this species in peridomestic and domestic areas, with the presence of infection by $T$. cruzi, thus showing the importance of maintaining epidemiological surveillance in relation to these species. Although T. jatai sp. nov. was caught in the wild environment, on rock outcrops located close to a settled area and although it was negative for $T$. cruzi, it was also recently found in a home on a ranch close to the type locality. This occurrence in an area with human activity shows that the importance of entomological surveillance focusing on $T$. costalimai should be extended to T. jatai sp. nov.

The subfamily Triatominae, for which up to the year 2012, 144 species had been recorded, with 62 occurring within Brazilian territory (Poinar 2005, Schofield \& Galvão 2009, Frias-Lasserre 2010, Gurgel-Gonçalves et al. 2012, Rosa et al. 2012), now with T. jatai sp. nov. numbers 145 species and 64 in Brazil.

Bionomic studies aiming to elucidate the vector potential of $T$. jatai sp. nov. for transmission of the parasite T. cruzi are being conducted.

\section{ACKNOWLEDGEMENTS}

To Anália Celencina Fagundes Gomes, Chagas disease manager of Health Department of the State of Tocantins, and to ENERPEIXE SA, for logistical support, to Cleber Galvão, from the LNIRTT/IOC/Fiocruz, for the T. williami specimens, to the biologists Leandro Borges Ramos and Simone Castro Simões de Souza, from the Laboratory of Leishmaniasis Transmitters/IOC/Fiocruz, for field collections, and to Ana Paula Rufino Amaro Santana, for maintaining the insectary.

\section{REFERENCES}

Bookstein FL 1990. Introduction to methods for landmark data. In Rohlf FJ, Bookstein FL (eds.), Proceedings of the Michigan morphometrics workshop, The University of Michigan (Museum of Zoology), Special Publication 2, Michigan Press, Ann Arbor, p. 215-225.

Campos R, Botto-Mahan C, Coronado X, Jaramillo N, Panzera F, Solari A 2011. Wing shape differentiation of Mepraia species (Hemiptera: Reduviidae). Infect Genet Evol 11: 329-333.

Carbajal de la Fuente AL 2007. Eco-genética comparativa das espécies afins Triatoma pseudomaculata Corrêa \& Espinola, 1964 e Triatoma wygodzinskyi Lent, 1951 (Hemiptera: Triatominae), $\mathrm{PhD}$ Thesis, Instituto Oswaldo Cruz, Rio de Janeiro, 218 pp.

Carbajal de la Fuente AL, Jaramillo N, Barata JMS, François N, Diotaiutu L 2011. Misidentification of two Brazilian triatomes, Triatoma arthurneivai and Triatoma wygodzinskyi, revealed by geometric morphometrics. Med Vet Entomol 25: 178-183.

Costa J, Almeida CE, Dotson EM, Lins A, Vinhaes M, Silveira AC, Beard CB 2003. The epidemiologic importance of Triatoma brasiliensis as a Chagas disease vector in Brazil: a revision of domiciliary captures during 1993-1999. Mem Inst Oswaldo Cruz 98: 443-449.

Costa J, Barth OM, Marchon-Silva V, de Almeida CE, Freitas-Sibajev MGR, Panzera F 1997. Morphological studies on the Triatoma brasiliensis Neiva, 1911 (Hemiptera, Reduviidae, Triatominae) genital structures and eggs of different chromatic forms. Mem Inst Oswaldo Cruz 92: 493-498.

Costa J, Lorenzo M 2009. Biology, diversity and strategies for the monitoring and control of triatomines - Chagas disease vectors. Mem Inst Oswaldo Cruz 104 (Suppl. I): 46-51.

Dujardin JP, Kaba D, Henry AB 2010. The exchangeability of shape. BMC Res Notes 3: 266

Frias-Lasserre D 2010. A new species and karyotype variation in the bordering distribution of Mepraia spinolai (Porter) and Mepraia gajardoi Frias et al. (Hemiptera: Reduviidae: Triatominae) in Chile and its parapatric model of speciation. Neotrop Entomol 39: 572-583.

Gaspe MS, Schachter-Broide J, Gurevitz JM, Kitron U, Gürtler RE, Dujardin JP 2012. Microgeographic spatial structuring of Triatoma infestans (Hemiptera: Reduviidae) populations using wing geometric morphometry in the Argentine Chaco. J Med Entomol 49: 504-514.

Gonçalves TCM, Mallet JRS, Ramos LB, Souza SCS, Lima NRC, Santos SM, Lopes CM 2006. Levantamento e monitoramento de triatomíneos em área de influência da Usina Hidrelétrica Peixe Angical (TO). Rev Soc Bras Med Trop 39 (Suppl. III): 157.

Gumiel M, Catalá S, Noireau F, Rojas de Arias A, García A, Dujardin JP 2003. Wing geometry in Triatoma infestans (Klug) and $T$. melanosoma Martinez, Olmedo \& Carcavallo (Hemiptera: Reduviidae). Syst Entom 28: 173-179.

Gurgel-Gonçalves R, Galvão C, Costa J, Peterson AT 2012. Geographic distribution of Chagas disease vectors in Brazil based on ecological niche modeling. J Trop Med 2012: 1-15.

IBGE - Instituto Brasileiro de Geografia e Estatística 2004. Mapa de bioma e vegetação Available from: ftp.ibge.gov.br/cartasemapas/ mapasmurais/biomaspdf.zip.

Lent H, Jurberg J 1980. Comentários sobre a genitália externa masculina em Triatoma Laporte, 1832 (Hemiptera, Reduviidae). Rev Bras Biol 40: 611-627.

Lent H, Wygodzinsky P 1979. Revision of the Triatominae (Hemiptera: Reduviidae) and their significance as vectors of Chagas disease. Bull Am Mus Nat Hist 163: 127-520.

Márquez E, Jaramillo-O N, Gómez-Palacio A, Dujardin JP 2011. Morphometric and molecular differentiation of a Rhodnius robustuslike form from $R$. robustus Larousse, 1927 and R. prolixus Stål, 1859 (Hemiptera, Reduviidae). Acta Trop 120: 103-109.

Matias A, de la Riva JX, Torrez M, Dujardin JP 2001. Rhodnius robustus in Bolivia identified by its wings. Mem Inst Oswaldo Cruz 96: 947-950.

Obara MT, Barata JMS, Rosa JA, Almeida PS, Gonçalves GA, Dale C, Gurgel-Gonçalves R 2012. Description of the female and new 
records of Triatoma baratai Carcavallo \& Jurberg, 2000 (Hemiptera: Heteroptera: Reduviidae: Triatominae) from Mato Grosso do Sul, Brazil, with a key to the species of the Triatoma matogrossensis subcomplex. Zootaxa 3151: 63-68.

Oliveira IAS, Maia AAS, Dantas EC 2008. Avaliação do controle de qualidade na identificação taxonômica e exame parasitológico de triatomíneos, indicadores de resultados discordantes e positividade, nos anos de 2004 a 2006. Boletim Epidemiológico Superintendência de Vigilância e Proteção a Saúde do Tocantins 5: 1-3.

Pires HHR, Barbosa SH, Jurberg J, Diotaiuti L 1995. Comparative studies of distinct populations of Triatoma infestans. V. Morphological patterns of the male genitalia. Mem Inst Oswaldo Cruz 90 (Suppl. I): 227.

Poinar JR 2005. Triatoma dominicana sp. n. (Hemiptera: Reduviidae: Triatominae) and Trypanosoma antiquus sp. n. (Stercoralia: Trypanosomatidae), the first fossil evidence of a Triatominae - Trypanosomatid vector association. Vector Borne Zoonotic Dis 5: 72-81.
Rohlf FJ 1996. Morphometric spaces, shape components and the effects of linear transformations. In LF Marcus, M Corti, A Loy, G Naylor, DE Slice (eds.), Advances in morphometric, NATO ASI Series A: Life Sciences, Vol. 284, Plenum Publishing, New York, p. 117-129.

Rosa JA, Rocha CS, Gardim S, Pinto MC, Mendonça VJ, Ferreira Filho JCR, de Carvalho EOC, Camargo LMA, de Oliveira J, Nascimento JD, Cilense M, Almeida CE 2012. Description of Rhodnius montenegrensis $\mathrm{n}$. sp. (Hemiptera: Reduviidae: Triatominae) from the state of Rondônia, Brazil. Zootaxa 3478: 62-76.

Schofield CJ, Galvão CJ 2009. Classification, evolution and species groups within the Triatominae. Acta Trop 110: 88-100.

Verano OT, Galvão AB 1959. Triatoma costalimai sp., n. Rev Bras Malar D Trop 10: 199-205.

Villegas J, Feliciangeli MD, Dujardin JP 2002. Wing shape divergence between Rhodnius prolixus from Cojedes (Venezuela) and Rhodnius robustus from Mérida (Venezuela). Infect Genet Evol 2: 121-128. 